\title{
ANALYZING BUYER BEHAVIOR WHEN SELECTING GREEN CRITERIA IN PUBLIC PROCUREMENT
}

\author{
Mieko Igarashi, Luitzen de Boer and Gerit Pfuhl*
}

\begin{abstract}
Given the complexity of green public procurement, decisions are likely to be driven by bounded rationality. However, we know little about what determines supplier selection criteria in any given situation. This study explores buyer behavior when considering environmental criteria. We first conducted interviews and identified 12 operational procedures used by buyers. We then developed a survey to explore the use of these procedures. Our quantitative analysis suggests that public buyers are motivated by their belief that they can make a difference. This is independent of buyers' experience or gender. However, their occupational position and the nature of a procurement seem to determine how buyers seek information about environmental criteria and which information source(s) they use. The data suggest that four specific decision-making heuristics are associated with their selected operational procedures.
\end{abstract}

\section{INTRODUCTION}

How do we make decisions? Many real-life decisions are complex, which prevents us from finding an analytical, optimal solution. We can perhaps measure or observe the outcome of a decision, that is, the alternative chosen. But what are the factors that lead to the decision?

* Mieko Igarashi, M.Sc., is a Ph.D. candidate, Norwegian University of Science and Technology. Her research focuses on green procurement, public procurement and sustainable supply chain management. Luitzen de Boer, Ph.D., is a Professor, Department of Industrial Economics and Technology Management, Norwegian University of Science and Technology. His teaching and research interests are in purchasing and supply management, public procurement, sustainability, cybernetics and system theory. Gerit Pfuhl, Ph.D, is an Associate Professor, Arctic University of Norway, and Researcher, Norwegian University of Science and Technology. Her research interests are in decision making under uncertainty, use of biases and heuristics and the study of rationality. 
How and where do we start to look for relevant information or advice? This seems more difficult to capture.

Study of the understanding of human behavior in organizational research was pioneered most notably by Simon (1947, 1957), and March and Simon (1958). Behavioral research has been referred to in different ways, such as behavioral economics (e.g., Tversky \& Kahneman, 1974), behavioral decision-making (e.g., Cyert \& March, 1963; Payne, Bettman, \& Johnson, 1993), and behavioral operations (e.g., Bendoly, Donohue, \& Schultz, 2006). The common interest of this research is how decisions are made in reality by individuals, a small group of individuals, or organizations. In the field of purchasing and supply management, the behavioral perspective has only in recent years started to receive broader attention (Carter, Kaufmann, \& Michel, 2007; Mantel, Tatikonda, \& Liao, 2006), especially with regard to supplier selection (Riedl, Kaufmann, Zimmermann, \& Perols, 2013). Interestingly, within the marketing literature research on organizational buying behavior has a much longer history, building on seminal studies by Webster and Wind (1972) and Sheth (1973). The main purpose of organizational buying behavior research, however, is to provide insights to marketers (Bunn, 1993; Webster \& Wind, 1972) rather than to develop more effective buying strategies. With the exception of Wilson, McMurrian, and Woodside (2001), who explicitly apply a behavioral decision-making perspective to the study of problem framing by buyers, organizational buying behavior research does not seem to be particularly rooted in the behavioral decision-making literature.

The importance of a behavioral perspective in green economy is illustrated by an Organisation for Economic Co-operation and Development (OECD) project called "Behavioural and Experimental Economics for Environmental Policy." This project, launched in 2013, recognizes the need to ensure that policy mechanisms have their intended impact and that behavioral economics can inform public policy (OECD, 2012). Since 2006, the EU has also executed a project concerning consumer behavior relating to the purchasing of environmentally preferable goods and has recently published a final report (Umpfenbach \& Colleagues Ecologic Institute, 2014). When it comes to green public procurement (GPP), the question is if we have enough insight into public buyer behavior in order to effectively inform GPP policy-makers. For example, determining the precise 
ANALYZING BUYER BEHAVIOR WHEN SELECTING GREEN CRITERIA

characteristics that a product or service must possess to be considered "environmental preferable" is a complex task (Coggburn \& Rahm, 2005). One may ask, "How do buyers decide on the environmental criteria to be included in tender documents?" The inclusion of environmental criteria in tender should favor the more environmentally sound products and hence promote the integration of environmental considerations into procurement process (Amann, Roehrich, Eßig, \& Harland, 2014). It is therefore important to understand how buyers establish a set of environmental criteria for each purchase.

In this study, we are interested in understanding buyer behavior by drawing on the main notion of behavioral decision-making, and in particular bounded rationality (Simon, 1947) and the related concept of heuristics (Newell \& Simon, 1972). Specifically, this study focuses on where and how buyers search for information and what kind of procedures they follow when considering which environmental criteria should be used in selecting suppliers. We compare our findings on considering environmental criteria to general descriptions of heuristics in the literature on bounded rationality. We expect that buyers will exemplify bounded rationality, especially in a green procurement context. This is because selecting suppliers while taking into account environmental aspects further complicates an already difficult decision, as it requires consideration of (a) multiple stages with possible additional environmental criteria (Igarashi et al., 2015) and (b) interaction between different categories of criteria from a long-term (life cycle) perspective (Preuss, 2002).

This paper seeks to explore buyer behavior in identifying or formulating potential environmental criteria and choosing concrete environmental criteria to be used in supplier selection. The first research question is: "What kind of contextual factors affect a buyer's environmental behavior?" The second question is: "Given the complexity of procurement decisions, how does bounded rationality as proposed in behavioral economics and psychology shape public buyers' behavior?" Gaining a better understanding of buyers' behavior when considering environmental criteria fills a gap in the GPP field. The implications of this research could lead to more effective GPP policies and practices in organizations. In addition, our research responds to the call by Flynn and Davis (2014) for a more clear application of theory in public procurement research. 
The structure of the paper is as follows. First, we outline the relevant literature and basic theoretical foundations. Second, we describe the research design and the collection of empirical data. Third, we present our quantitative data analysis, followed by discussion and interpretation of the results. The paper ends with conclusions, implications for policymakers and researchers, and a discussion of the study's limitations.

\section{THEORETICAL FOUNDATION AND LITERATURE REVIEW}

In this section, we first present and explain the core theoretical concepts used in this study: bounded rationality and heuristics. Next, we introduce the concept of information sources based on organizational buying behavior literature. The research questions and theoretical perspectives in this paper, and their relationships, are summarized in Figure 1. We then review the relevant literature in the area of public procurement. Finally, review is provided with a particular focus on existing discussions related to buyer behavior.

We would like to note that, for the sake of consistency, we use "buyer" instead of terms such as "purchaser" and "procurer." We have chosen "buyer" as it is the most general term. Because terminology for buying activities varies from field to field, we try to keep our usage within the established terminology. We therefore use "procurement" for public procurement, "purchasing" for purchasing and supply management, and "buying" for organizational buying behavior, without implying that these activities are different.

\section{Model of Bounded Rationality and Heuristics}

The original statement by Simon (1947, p. 79) on bounded rationality declared:

It is impossible for the behavior of a single, isolated individual to reach any high degree of rationality. The number of alternatives he must explore is so great, the information he would need to evaluate them so vast ... Individual choice takes place on an environment of 'givens' - premises that are accepted by the subject as bases for his choices; and behavior is adaptive only within the limits set by these 'givens.' 
ANALYZING BUYER BEHAVIOR WHEN SELECTING GREEN CRITERIA

In Simon's description, cognitive limitations are emphasized. Later, "task environment" became another important element of bounded rationality in his research: "Human rational behavior is shaped by a scissors whose two blades are the structure of task environments and the computational capabilities of the actor" (1990, p. 7). Following Simon's emphasis on these two elements, Payne et al. (1993) proposed to extend the factors influencing decision-making behavior to task-related, personal, and social context characteristics. Prior task knowledge and expertise can represent personal characteristics, and accountability to others can be an example of social context (Payne et al., 1993). Task-related characteristics include both the nature and context of a task. Another essential notion in Simon's model of bounded rationality is "satisficing." Human beings use satisficing processes to achieve reasonable solutions, given the sheer complexity of the environment and the limited economic and cognitive resources available to them (Simon, 1957).

For some researchers, bounded rationality is more or less synonymous with heuristics and biases (Gigerenzer \& Goldstein, 1996; Lopes, 1992). "Heuristics and biases," as represented by Tversky and Kahneman (1974), retain the normative kernel of the classical rationality, and their empirical observations reveal that important principles of rational choice are often violated in the real world (Loock \& Hinnen, 2015). Simon argued that the minds of living systems should be understood relative to the environment in which they evolved, rather than to the tenets of classical rationality (Gigerenzer \& Goldstein, 1996). Heuristics are defined in different ways (Chow, 2014), and definitions have changed over time. A comprehensive discussion on the definitions of heuristics is beyond our scope. We shall use the following definition based on Newell and Simon (1972): "Heuristics are cognitive shortcuts that emerge when information, time, and processing capacity are limited" (Bingham \& Eisenhardt, 2011, p. 1439).

One representative type of heuristics could be Simon's "satisficing" (Grandori, 1984). "Satisficing" refers to an approach where a decision-maker stops the search for a solution as soon as a solution is found that exceeds a minimal aspiration level. Aspiration levels may be adjusted along the way, depending on the experienced effort required for finding possible solutions (Simon, 1955). Some 
other examples of specific heuristics are "recognition heuristics," in which solutions are chosen because they are recognized or more familiar than other solutions (Goldstein \& Gigerenzer, 2002), and "availability heuristics," in which a decision-maker may focus on information that is easier to retrieve or easier to imagine (Tversky \& Kahneman, 1974). We will discuss if buyers use those heuristics after presenting our results.

In summary, we adopt the original concept of bounded rationality by Simon as the central theoretical lens for our study. We aim to analyze if and to what extent contextual factors seem to influence buyers' behavior and to identify the heuristics used by public buyers.

\section{Concept of Organizational Buying Behavior}

Understanding how organizations behave when they are confronted with a complex purchase has been of great interest to the marketing field for a long time (Grønhaug, 1975; Sheth, 1973; Webster \& Wind, 1972). More specifically, the search for information has long been recognized as an important phase in the organizational buying process (Brossard, 1998; Bunn \& Clopton, 1993; Dempsey, 1978), as well as the classification of buying situations (Robinson, Faris, \& Wind, 1967). Information sources are used to search for a solution to the problem, and existing studies refer to numerous sources, such as buying records, communications within an organization, visits to suppliers' facilities, and so forth (Brossard, 1998; Dempsey, 1978). These sources are classified by several dimensions: personal/impersonal, commercial/non-commercial (Moriarty \& Spekman, 1984), and internal/external (Brossard, 1998; Dempsey, 1978). The existing literature includes an examination of informational sources for identifying and evaluating potential goods, services, technology, suppliers, or new investments typically in the context of industrial buying. There is no reason for not applying these insights to public buyers. Accordingly, we adopt a similar differentiation in our study, i.e., distinguishing between internal and external information sources. We further divide internal information sources into sources within the buyer's own department and outside the buyer's department though within the buyer's organization. In this way, we can more precisely investigate which type of informational resources buyers consult when considering environmental criteria than if we divided sources only between internal and external. Our classifications are: buyer internal information sources ("BIS"), in- 
house information sources ("InIS"), and external information sources ("ExtIS"). We want to see if buyers rely on information sources differently depending on their personal characteristics, organizational profiles, and buying project types. To the best of our knowledge, no previous research has investigated how public buyers search for information as part of identifying and considering environmental criteria in supplier selection. Figure 1 summarizes the theoretical framework for this study.

FIGURE 1

Theoretical Framework and Research Questions

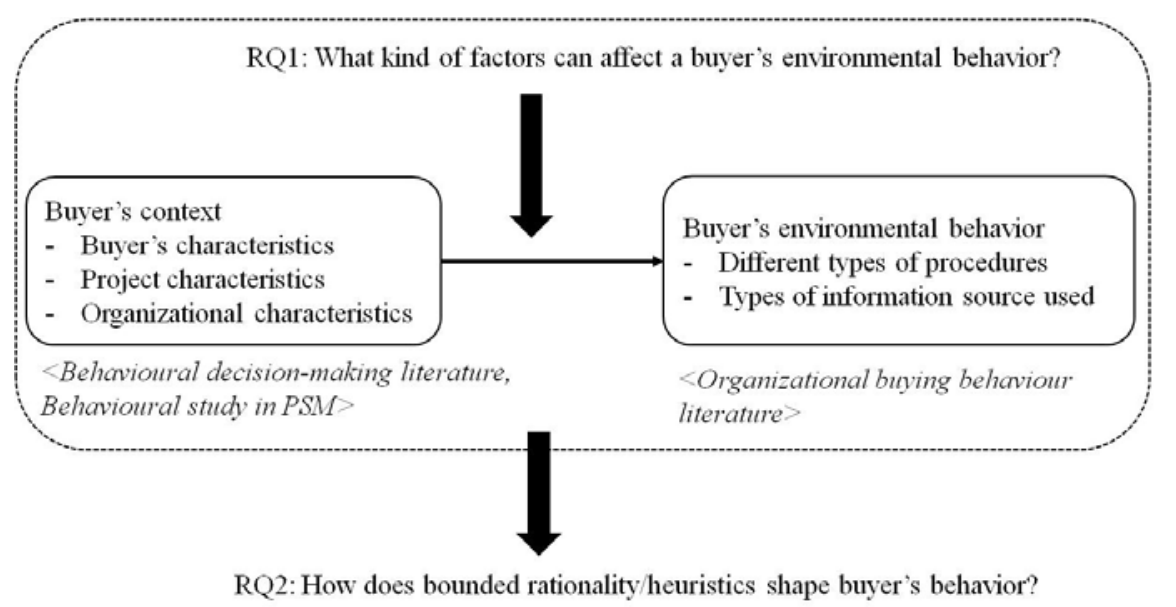

RQ2: How does bounded rationality/heuristics shape buyer's behavior?

\section{A Review of Key Studies of Green Public Procurement}

In this section, we provide a review of the relevant literature in the area of public procurement, in particular literature on GPP. In the first issue of the Journal of Public Procurement, Thai (2001) addressed environmental issues; environmental protection is present in every country, and environmental pressure is increasingly placed on public procurement professionals. GPP has become an important issue in public procurement during the last few decades. The basic concept of GPP relies on having clear and ambitious environmental criteria for products and services (The Commission of the European 
Communities, 2008). Thus, the first distinct topic in existing GPP research papers assessed the use of environmental criteria in the procurement process, covering a wide range of products and services. The geographical scopes of these studies vary, but have included Nordic countries (Kippo-Edlund, Hauta-Heikkilä, Miettinen, \& Nissinen, 2005; Nissinen, Parikka-Alhola, \& Rita, 2009; Palmujoki, Parikka-Alhola, \& Ekroos, 2010; Parikka-Alhola, Nissinen, \& Ekroos, 2006), Norway (Michelsen \& de Boer, 2009), Europe, North America, Asia (Brammer \& Walker, 2011), and Italy (Testa, Iraldo, Frey, \& Daddi, 2012). In addition to these articles, reports delegated by the European Commission also discuss the status of inclusion of environmental criteria in public procurement (Bouwer, de Jong, Jonk, Berman, Bersani, Lusser, Nissinen, Parikka \& Szuppinger, 2005; CEPS \& College of Europe, 2012). These studies demonstrated two approaches to measuring and examining the status of environmental considerations: use of secondary data, i.e., auditing tender documents (e.g., Nissinen et al., 2009; Parikka-Alhola, 2008) and contract clauses (Palmujoki et al., 2010), and primary data gathering, i.e., distributing survey questionnaires and/or conducting interviews (e.g., Bouwer et al., 2005; Michelsen \& de Boer, 2009).

The second topic concerns specific issue in the implementation of GPP in certain types of procurement products/services. Products/services addressed include furniture (Parikka-Alhola, 2008), building design services (Sporrong \& Bröchner, 2009), and construction work (Faith-Ell, Balfors, \& Folkeson, 2006; Varnäs, Balfors, \& Faith-Ell, 2009). Faith-Ell et al. (2006) examined the fulfillment and follow-up of environmental requirements, while others typically investigate the different types of environmental criteria used in the procurement process.

The third topic deals with drivers and determinants of, and incentives, obstacles, or/and barriers to GPP. While the geographical contexts and products or services addressed vary among studies, various researchers have identified drivers for and barriers to GPP from the individual level, the organizational level, and the interorganizational level (Coggburn \& Rahm, 2005; Faith-Ell et al., 2006; Geng \& Doberstein, 2008; Grandia, Steijn, \& Kuipers, 2015; Li \& Geiser, 2005; Michelsen \& de Boer, 2009; New, Green, \& Morton, 2002; Palmujoki et al., 2010; Preuss, 2007; Rizzi, Frey, Testa, \& Appolloni, 2014; Testa et al., 2012; Varnäs et al., 2009; Walker, Di Sisto, \& MaBain, 2008; Zhu et al., 2013). GPP is enhanced through 
government leadership; application of LCC; establishment of GPP criteria; awareness of GPP initiatives and supporting tools; regulatory compliance, monitoring, and pressure from stakeholders; organizational value; and value champions. Other factors such as organizational size and the existence of a purchasing department and strategy also play a role. A range of factors that negatively influence GPP are commonly identified, including a deficient of information sharing or communications about environmental performance, lack of clarity in regulations or organizational structure, and lack of awareness/knowledge of environmental issues. Psychological and social factors have also been highlighted, such as fear of increased cost and personal motivation, lack of systematic monitoring of requirements, and lack of a long-term strategy. Appendix A provides a list of relevant research and indicates drivers and barriers addressed in the research.

We have also identified other themes. For example, Swanson, Weissman, Davis, Socolof, and Davis (2005) developed a tool that determines priority product categories for green procurement based on technical and institutional criteria. The role of GPP in the integration of environmental product policies was examined by $\mathrm{Li}$ and Geiser (2005). The integration of GPP in the pre-decision phase of an environmental impact assessment (EIA) was discussed by Uttam, Faith-EII, and Balfors (2012). Bratt, Hallstedt, Robèrt, Broman, and Oldmark (2013) assessed the process of developing sustainable criteria for public procurement in a Swedish governmental expert body. Finally, an analysis of procurement files (Amann et al., 2014) demonstrated that the inclusion of environmental indicators strongly influenced offers from suppliers and moderately influenced awards of environmental products/services. Several studies have analyzed the functioning of GPP as an environmental policy instrument from a costeffective perspective (Lundberg \& Marklund, 2013; Lundberg, Marklund, Strömbäck, \& Sundström, 2015).

There is a handful of research that discusses buyer behavior in green procurement. Preuss and Walker (2011) observed buyer's cognitive and affective barriers to sustainable public procurement, such as cognitive limitations due to an excess of information, motivational differences among managers, lack of training, and lack of information as opposed to plentiful information. Walker et al. (2008) identified inertia by project stakeholders to be another barrier. 
Similarly, Alberg Mosgaard (2015) argued that green procurement is a habit-forming part of everyday practice, and that it matters if purchasers actually put their knowledge into practice. A value-related dimension is mentioned in several studies. Walker et al. (2008) pointed out value champions in buying organizations. Grandia et al. (2015) identified direct and indirect factors that influenced a buyer's sustainable procurement behavior based on organizational change theory. They found that individual values and beliefs played an important role in the use of potential sustainable procurement. Li and Geiser (2005) argued that psychological and social factors, such as personal motivation, uncertainty, and commitment to environmental quality improvement, influence organizations' buying processes. In an assessment of tender documents, Igarashi, de Boer, and Michelsen (2015) found buyer's cognitive strategies in dealing with the inclusion of environmental criteria: "ignore," "incorporate," "insist," and "integrate."

Despite this being a non-exhaustive review, it is clear that there has been little focus placed on public buyers themselves (Flynn \& Davis, 2014) in discussion of GPP. So far, affective and habitual elements have emerged as influential individual factors.

\section{Behavioral Studies in Purchasing and Supply Management}

Factors that can influence a buyer's decision-making are a major topic in behavioral studies on purchasing and supply management. Qualls and Puto (1989) found that whether or not a buyer frames a decision-making situation as positive or negative can depend on organizational climatic factors, such as work environment and the availability of bonuses. It has also been argued that decision frames affect the outcome of the decision-making process. Mantel et al. (2006) revealed that make-or-buy evaluations were influenced by environmental factors such as the vividness of the information and perceived risk. Riedl et al. (2013) also argued that organizational, situational, and personal characteristics influence the extent of rationality in supplier selection. Furthermore, their study found some differences in the effects of those characteristics between two countries. Wilson et al. (2001) found that how buyers frame purchasing problems influences their preferences towards vendor offerings. Another finding from their study concerns the use of heuristics, not only for making choices among alternatives, but also for deciding on processes - that is, deciding on how to decide. 
Another popular topic in the literature is finding or defining certain types of heuristics. Barclay and Bunn (2006) observed two different types of process heuristics by comparing the situational category of a buying project to the actual decision approach based on a taxonomy of the buying situation. "Structuring heuristics" concerns cases where buyers rely on highly structured and rational buying activities in buying projects that are not classified as such. "Downgrading heuristics" apply to the tendency of buyers to perform lower levels of buying activities than might be expected in a given situation. Heuristics used in customer-supplier relationships have also been reported by Guercini, La Rocca, Runfola, and Snehota (2015). These researchers categorize three types of heuristics used in face-to-face meetings and in preparation for meetings, respectively. Their study further argues that individuals involved in customer-supplier relationships use a portfolio of heuristics that are personal and experience related.

Carter et al. (2007) made an extensive list of decision-biases by reviewing the existing literature on economics, psychology, and organizational decision-making, and developed a taxonomy of nine decisional biases that can impact supply management. They argued that these biases can negatively impact decision-making effectiveness and positively impact decision-making efficiency.

To summarize, various factors influence a buyer's decision frames or way of problem framing in different situations. Several types of heuristics have been described in purchasing and supply management. However, little is known about buyer behavior in environmental procurement and/or public procurement.

\section{METHODS}

In this study, we employ a mixed method design (Tashakkori \& Teddlie, 2003). We first collected qualitative data through interviews then used the results to develop a survey to collect quantitative data. Using a qualitative method as a first step was appropriate in our study because we explored a phenomenon about which little has been known: buyers' behavior in considering environmental criteria. A subsequent quantitative method was needed because we looked for possible relationships between contextual factors and buyer behavior. The mixed method advantage has been described as 
follows: "By using more than one method within a study, we are able to obtain a more complete picture of human behavior and experience" (Morse, 2003).

\section{Interviews}

As the first phase of data collection, in 2013 we conducted interviews with two buyers from two Norwegian public organizations. To gain a deeper understanding of public procurement practices and processes, semi-structured interviews were conducted multiple times with one of the buyers amounting to five hours in total. The second buyer from another organization was invited to one semi-structured interview. The informants were both procurement project leaders in their respective organizations. They were asked to recall their latest project related to ICT equipment, and the authors assessed the corresponding tender documents prior to the interviews. During the interviews, the buyers were asked mainly about how they came to use certain environmental criteria/requirements, what these criteria referred to, from whom they received advice, and so on. When a tender did not include environmental criteria as a form of specific requirements (qualification, specification, or award criteria), they were asked about the source of information on which they based their decision to not include environmental requirements. Each interview lasted about one hour, and each interview was transcribed. If needed, follow-up questions were asked via e-mail or phone.

From these interviews, we identified different types of informationseeking attempts and actions that each interviewee either had or could have taken if the related information sources had been available when they considered the environmental criteria for each specific project. We term different types of attempts and actions "operational procedures," noting that they influence organizational decisions and are intended to secure, condense, and evaluate information (Cyert \& March, 1992). After aggregating similar procedures across the interviewees, we identified 12 different operational procedures, as shown in Table 1. These operational procedures include both attempts to search information sources for possible environmental criteria and actions that could directly or indirectly influence the decision whether or not to adopt specific environmental criteria. The operational procedures we identified even contain the buyer's attitude toward including environmental criteria in the procurement process. 
One more interview was conducted in 2015 to confirm our list of buyers' operational procedures from the previous interviews. The third interviewee was a buyer from another type of public organization in Norway. The contents and method of the interview followed the approach of the previous interviews. As a result of this interview, we

TABLE 1

Operational Procedures Identified from the Interviews

\begin{tabular}{|l|l|l|l|}
\hline Operational procedure (short label) & \multicolumn{2}{|l|}{ Interviewees } \\
\hline & \#1 & \#2 & \# 3 \\
\hline $\begin{array}{l}\text { I look at what we have done in previous similar projects and } \\
\text { update what should be changed (PreUp). }\end{array}$ & & \\
\hline $\begin{array}{l}\text { I believe that one can contribute to environmental issues as } \\
\text { a buyer (Belv). }\end{array}$ & $\checkmark$ & & \\
\hline $\begin{array}{l}\text { I consult with an environmental expert within or external to } \\
\text { the organization (EnvExp). }\end{array}$ & $\checkmark$ & $\checkmark$ & \\
\hline $\begin{array}{l}\text { I investigate what is state of the art in the supply market } \\
\text { (Mkt). }\end{array}$ & $\checkmark$ & & $\checkmark$ \\
\hline $\begin{array}{l}\text { I check similar procurement projects done by other } \\
\text { authorities (OthAut). }\end{array}$ & $\checkmark$ & & \\
\hline $\begin{array}{l}\text { I check relevant legal documents and see what criteria } \\
\text { should be met (LegDoc). }\end{array}$ & $\checkmark$ & & \\
\hline $\begin{array}{l}\text { I apply the environmental criteria that we are told to use (by a } \\
\text { central procurement department or any other internal team) } \\
\text { (ToUse). }\end{array}$ & & $\checkmark$ & \\
\hline $\begin{array}{l}\text { If there are a lot of qualifications and specifications, award } \\
\text { criteria cannot be as powerful (QuISpc). }\end{array}$ & $\checkmark$ & & \\
\hline $\begin{array}{l}\text { I ask a product expert on our project team to give advice } \\
\text { (ProExp). }\end{array}$ & $\checkmark$ & $\checkmark$ & $\checkmark$ \\
\hline $\begin{array}{l}\text { I consider environmental standards in the industry (but then I } \\
\text { do not demand the same aspect) (IndReq). }\end{array}$ & $\checkmark$ & & \\
\hline $\begin{array}{l}\text { I apply environmental criteria we usually use in similar } \\
\text { product procurements (FolUsu). }\end{array}$ & & $\checkmark$ & $\checkmark$ \\
\hline $\begin{array}{l}\text { I look at the environmental criteria recommended by Difi* or } \\
\text { the EU guidelines (GudCri). }\end{array}$ & $\checkmark$ & $\checkmark$ & \\
\hline
\end{tabular}

Notes: *Difi: "Direktoratet for forvaltning og IKT," under Fornyings- og administrasjons- og kirkedepartementet (FAD), the Norwegian agency for public management and eGovernment.

found some procedures that were used in common, but no additional types of procedures were identified (Table 1). Identifying all possible 
operational procedures was not the purpose of this qualitative data gathering. As will become clear below, we were more interested in measuring the importance of these procedures for the buyers themselves.

A brief explanation concerning some of the procedures we identified from the interviews is worth noting here. Consultation with environmental experts ("EnvExp" in Table 1) was mentioned, but this procedure did not lead to the inclusion of concrete environmental criteria. The buying authority of interviewee 1 obtained advice on an environmental aspect of the procurement project from an environmental organization (which was subsequently not included in the demands due to practical issues). Interviewee 1 also stated that they do not have any environmental specialists within their organization. A similar statement was made by interviewee 2, suggesting that no environmental specialist was available within the department. Interviewee 3 described a procurement project concerned with technical equipment, i.e., IC chips. For this concrete procurement the market is rather small. Environmental requirements were thus not set so that the number of suppliers who could deliver a bid was not limited.

\section{Survey on the Ranking of Operational Procedures and Their Applicability}

We designed a questionnaire survey based on our interview findings. The 12 operational procedures identified are the main measurement devices in the survey. It should be noted that the wording of some operational procedures was not identical to that used in Table 1 (see Appendix B). For example, the EnvExp behavioral pattern was changed to "I consult with an environmental expert in our organization" in order to specify whether we meant an internal or external environmental expert, and to couple with ProExp, which concerns internal experts. Before running the actual survey, we ran a brief pilot with two buyers to ensure that the questions we used were understandable and that the description of operational procedures did not too specifically match the interview cases. The main survey was subsequently run from February to March 2014 and from August to September 2015. Since no exhaustive list of Norwegian public buyers was available, the survey invitation was sent to counties' and municipalities' email addresses in the first round, and to buyers' network mailing lists that were available to the authors in the second 
round. Two weeks after the first invitation, a reminder was sent. During the first survey period, the survey link was also put on the website of a project activity (https://www.ntnu.edu/iot/gvc) in which the authors' affiliated department played a leadership role. The survey was run in Norwegian, whereas all the interviews were conducted in English due to the language preferences of the main interviewer. The survey was approved by Norwegian Social Science Data Services (NSD), the data protection official for research in Norway.

We used a five-point Likert-type scale in which $1=$ "strongly disagree," 2 = "disagree somewhat," 3 = "neither disagree nor agree," 4 = "somewhat agree," and 5 = "strongly agree." Importantly, "not relevant" was an option for each question. Respondents were asked to indicate the degree to which they considered each operational procedure applicable to their decision in their most recent procurement project. To help them think of a particular recent project when scoring the questions, they were asked to describe their most recent procurement project. Respondents could also give free descriptions of operational procedures if they followed ones different from those listed in the survey. A hypothetical procurement case ("imagine procuring smart glasses"), which was identical for all respondents, was included at the end. We asked the respondents to imagine how many offers they might receive to ensure that they imagined the purchase of such a product as vividly as possible.

The unit of analysis was an individual buyer's behavior in a single procurement project. Organizational buying decisions can involve several individuals in an organization, or they can be the responsibility of one individual. The perceived potential of alternative suppliers and brands to satisfy a number of objectives in any particular buying decision is determined by the interaction of many factors, such as the backgrounds of individuals, information sources and active searches, perceptual distortion, and satisfaction with past purchases (Sheth, 1973). In addition, a buyer as an individual working in a buying department or team is bound by the formal organization, which is likewise embedded in the influence of the broader environment (Webster \& Wind, 1972). Thus, it is not easy to comprehensively understand factors influencing the implementation of GPP. Our study has a micro focus on individual buyer behavior and includes possibly related contextual factors when considering 
environmental criteria, but not organizational factors such as team management and leadership capacity as studied in organizational change research (e.g., Nelson, Wood, \& Gabris, 2011).

\section{Respondent Profile}

The demographic information gathered included buyer characteristics, such as gender, age, occupational position, experience as a buyer; organizational characteristics, such as organizational size and type of organization; project characteristics, such as the product category of a recent procurement project on which the respondent based her or his answers and the number of offers they actually received. We gathered this information to capture the concept of "task environment" as advocated by Simon (1990) and Payne et al. (1993). We asked for the type of organization (public or private sector) to assure that the respondents were from public authorities, since we expected that the survey could be forwarded to private organizations, too. Out of 67 recorded responses, 62 respondents worked in a public organization; these were included in the subsequent data analyses. One respondent did not tell us his/her gender and age but answered all other items. The demographic profile of respondents is provided in Table 2.

TABLE 2

Respondent Profile

\begin{tabular}{|l|l|l|l|l|l|}
\hline Gender & $\mathrm{N}=61$ & Organizational size & $\mathrm{N}=62$ & Position & $\mathrm{N}=55$ \\
\hline male & 34 & $<250$ & 19 & employee & 26 \\
\hline female & 27 & $>=250$ & 43 & project leader & 13 \\
\hline Age & $\mathrm{N}=61$ & Experience & $\mathrm{N}=58$ & department leader & 16 \\
\hline$<39$ & 12 & $<1$ year & 7 & $\begin{array}{l}\text { Procurement } \\
\text { category }\end{array}$ & $\begin{array}{l}\mathrm{N}=56 \\
(59 *)\end{array}$ \\
\hline $40-49$ & 21 & $1-5$ years & 15 & Goods & $31(34)$ \\
\hline $50-59$ & 18 & $5-10$ years & 18 & Works & 3 \\
\hline$>60$ & 10 & $>10$ years & 18 & services & 22 \\
\hline
\end{tabular}

Notes: *Three respondents did not tell us their latest procurement category, but indicated "goods procurement" in their general responsible category.

ANALYSIS AND RESULTS 
ANALYZING BUYER BEHAVIOR WHEN SELECTING GREEN CRITERIA

\section{General Analysis of Buyer Behavior}

First, we present our findings using descriptive statistical analysis insofar as buyers agreed on each operational procedure. We estimated that the response rate for counties and municipalities accounts for about $10 \%$ and the buyers' network for about $28 \%$. But this is a maximum response rate because some who received a survey invitation may forward it to other buyers.

"QulSpc" was reverse coded because low points for QulSpc mean that buyers think that environmental award criteria can be powerful with the use of environmental requirements as a qualification. A rating of "IndReq" turned out to be ambiguous. Buyers who include environmental demands that are already treated in industrial standards could agree or disagree with that question. For any subsequent analyses of scores, we therefore excluded it. We could, however, still use the data for determining whether respondents regarded the procedure as applicable.

We looked at how applicable each operational procedure is by calculating how many respondents gave it more than one point in their scores. In other words, we determined how many respondents thought that each operational procedure could be made available or could be used. If respondents said "disagree" (2 in Likert scale) to a certain operational procedure, that meant that they were aware of informational sources that could be used, but were not used in the latest procurement on which they based their answers. This is shown as "applicability" in Table 3 and 4.

Most buyers ( $n=32$ ) agreed to some extent with all 12 operational procedures. However, a few buyers agreed with only one $(n=2)$ or two $(n=2)$ operational procedures. This might indicate that the use of operational procedures depends on each procurement case, as was also indicated by the survey responses in which some buyers offered free descriptions of other possible operational procedures. But we saw only a handful of such cases.

Looking at the agreement scores (mean and SD) for the actual procurement scenario (Table 3), "Belv" ranked highest, ahead of the second ranked behavior "LegDoc," with as many as 0.48 points. After "LegDoc," seven patterns followed by small intervals; that is, in total the difference was 0.5 between the second and eighth-ranked terms. 
The lowest ranked patterns were "EnvExp" and "QuISpc." Despite "QuISpc" being ranked low, most buyers regarded it as a relevant pattern. This was not the case for "ProExp" and "EnvExp," as 19\% of the buyers regarded them as inapplicable.

For the imagined procurement of the same product for all buyers (Table 3), we found a very similar ranking. The procedure most agreed on was "Belv," which was 0.53 ahead of the second highest agreed pattern ("PreUp"). Notably, "EnvExp" increased by .43. Furthermore, asking an expert, either a product "ProExp" or an environment "EnvExp," was again regarded as inapplicable by $24 \%$ of the buyers.

For the next part of our analysis, we excluded the three work procurement projects. That is, we looked at rankings of goods and services procurement projects separately (Table 4). Both goods and services buyers gave "Belv" the highest scores, but rankings of other operational procedures and score distributions were considerably

TABLE 3

Descriptive Statistics, Actual and Hypothetical Procurement

\begin{tabular}{|c|c|c|c|c|c|c|c|}
\hline \multicolumn{4}{|c|}{ Latest procurement, $n=59$} & \multicolumn{4}{|c|}{ Hypothetical procurement, $n=42$} \\
\hline $\begin{array}{l}\text { Proce- } \\
\text { dure }\end{array}$ & $\begin{array}{l}\text { Applica- } \\
\text { bility (\%) }\end{array}$ & Mean \pm SD & Rank & $\begin{array}{l}\text { Proce- } \\
\text { dures }\end{array}$ & $\begin{array}{l}\text { Applica- } \\
\text { bility (\%) }\end{array}$ & Mean \pm SD & Rank \\
\hline Belv & 100 & $4.16 \pm .09$ & 1 & Belv & 100 & $4.29 \pm .10$ & 1 \\
\hline LegDoc & 97 & $3.68 \pm .13$ & 2 & PreUp & 88 & $3.76 \pm .10$ & 2 \\
\hline FolUsu & 88 & $3.63 \pm .13$ & 3 & OthAut & 90 & $3.66 \pm .13$ & 3 \\
\hline GudCri & 93 & $3.61 \pm .14$ & 4 & LegDoc & 93 & $3.56 \pm .15$ & 4 \\
\hline ToUse & 86 & $3.54 \pm .17$ & 5 & FolUsu & 90 & $3.50 \pm .15$ & 5 \\
\hline PreUp & 84 & $3.51 \pm .15$ & 6 & GudCri & 93 & $3.44 \pm .18$ & 6 \\
\hline OthAut & 98 & $3.46 \pm .14$ & 7 & Mkt & 79 & $3.42 \pm .15$ & 7 \\
\hline ProExp & 83 & $3.40 \pm .17$ & 8 & EnvExp & 76 & $3.41 \pm .28$ & 8 \\
\hline Mkt & 88 & $3.18 \pm .15$ & 9 & ToUse & 79 & $3.39 \pm .19$ & 9 \\
\hline QuISpc & 97 & $3.02 \pm .14$ & 10 & ProExp & 76 & $3.38 \pm .16$ & 10 \\
\hline EnvExp & 83 & $2.98 \pm .16$ & 11 & QuISpc & 98 & $2.90 \pm .14$ & 11 \\
\hline IndReq & 86 & & & IndReq & 88 & & \\
\hline
\end{tabular}


ANALYZING BUYER BEHAVIOR WHEN SELECTING GREEN CRITERIA IN PUBLIC PROCUREMENT

TABLE 4

Descriptive Statistics, Goods and Services Procurement

\begin{tabular}{|l|l|l|l|l|l|l|l|}
\hline \multicolumn{3}{|l|}{ Goods procurement, $\mathrm{n}=34$} & \multicolumn{5}{l|}{ Service procurement, $\mathrm{n}=22$} \\
\hline $\begin{array}{l}\text { Proce- } \\
\text { dure }\end{array}$ & $\begin{array}{l}\text { Applica- } \\
\text { bility (\%) }\end{array}$ & Mean \pm SD & Rank & $\begin{array}{l}\text { Proce- } \\
\text { dure }\end{array}$ & $\begin{array}{l}\text { Applica- } \\
\text { bility }(\%)\end{array}$ & Mean \pm SD & Rank \\
\hline Belv & 100 & $4.16 \pm 0.63$ & 1 & Belv & 100 & $4.13 \pm 0.69$ & 1 \\
\hline FolUsu & 91 & $3.62 \pm 0.94$ & 2 & LegDoc & 100 & $4.04 \pm 0.71$ & 2.5 \\
\hline GudCri & 97 & $3.45 \pm 0.99$ & 4 & OthAut & 100 & $4.04 \pm 0.56$ & 2.5 \\
\hline LegDoc & 97 & $3.45 \pm 1.12$ & 4 & GudCri & 91 & $3.86 \pm 1.01$ & 4 \\
\hline ToUse & 97 & $3.45 \pm 1.18$ & 4 & ProExp & 87 & $3.80 \pm 1.01$ & 5 \\
\hline PreUp & 97 & $3.35 \pm 1.14$ & 6 & PreUp & 74 & $3.76 \pm 0.75$ & 6 \\
\hline ProExp & 84 & $3.11 \pm 1.19$ & 7 & ToUse & 78 & $3.67 \pm 1.28$ & 7 \\
\hline QuISpc & 100 & $3.03 \pm 0.97$ & 8.5 & FolUsue & 87 & $3.65 \pm 0.93$ & 8 \\
\hline OthAut & 100 & $3.03 \pm 1.09$ & 8.5 & Mkt & 83 & $3.47 \pm 0.90$ & 9 \\
\hline Mkt & 97 & $2.97 \pm 1.08$ & 10 & EnvExp & 78 & $3.11 \pm 0.96$ & 10 \\
\hline EnvExp & 91 & $2.90 \pm 1.21$ & 11 & QuISpc & 96 & $2.91 \pm 1.19$ & 11 \\
\hline IndReq & 91 & & & IndReq & 87 & & \\
\hline
\end{tabular}

different between goods and services. In goods purchases, there was a score difference of 0.5 between the first ranked and the second highest ranked behavior, "FolUsu." The next six behavioral patterns were found to have the same-sized interval of 0.5 points. On the contrary, in service purchases, there were only small intervals after the first to the eighth, totaling 0.5 points. Another difference was that "PreUp" and "ToUse" were identified as not relevant by over $20 \%$ of those procuring services, but by only one respondent who purchased goods.

A further interesting point is that services buyers gave higher scores than goods buyers to most of the operational procedures. Those procuring services agreed more strongly on "OthAut" $(F(1,50)=$ 13.441, $\mathrm{p}=.001, \eta 2=.212)$ and "LegDoc" $(\mathrm{F}(1,49)=4.386, \mathrm{p}$ $=.041, \mathrm{\eta} 2=.082)$. 
In summary, "Belv" was clearly supported by buyers in any procurement context. Agreement to the other operational procedures was influenced by the type of procurement; that is, it mattered if one purchased a service or goods. Furthermore, "Belv," "LegDoc," "OthAut," "GudCri," and "QuISpc" were relevant for nearly all buyers, whereas "PreUp," "ProExp," and "EnvExp" were not relevant for up to $20 \%$ of the buyers.

\section{Regression Analysis}

We looked at whether any of the 11 operational procedures were influenced by either the buyer profile - that is, gender, occupational position, buyer experience, organizational size - or by the project profile - that is, the product category and number of offers in the actual procurement project. Since age correlated highly with experience (Spearmans rho $=.505, p<.001$ ), we did not include age in the regression model. We were interested in whether the buyer profile affected the agreement toward an operational procedure and whether the procurement project affected the agreement. Accordingly, we ran two separate regression analyses. The first type of regression had as predictors all buyer profile variables. The second regression type had as predictors the type of procurement and the number of offers. We recoded the number of offers into low, medium, and many, with low equaling less than two offers, medium with two to four offers, and many with more than five offers. Unfortunately, roughly one-third of buyers did not fill in the number of offers they received.

First, we looked at whether the buyer profile and organizational size influenced any of the 11 operational procedures (note that "IndReq" was ambiguous and removed for this analysis). We found only one significant relationship. Higher positioned buyers looked more into the market when considering environmental criteria; i.e., the regression equation yielded $F(3,43)=2.827, p=.05$ with an $R^{2}$ of .165 for "Mkt.," with "position" significantly predicting the agreement to "Mkt" [B $=-.406, t(50)=-2.062, p=.045]$. None of the other operational procedures were associated with buyer profile or organizational size.

Second, we performed regression analyses with the project profiles as predictors. We had already seen that product category influenced "OthAut" and "LegDoc" in the previous section. Including 
ANALYZING BUYER BEHAVIOR WHEN SELECTING GREEN CRITERIA

IN PUBLIC PROCUREMENT

the number of offers did not yield any new associations. Nor were any other operational procedures influenced by the type of procurement or the number of offers.

Last, we looked at agreement to the operational procedures. Here we used only applicable procedures and defined scores larger than three to mean that a buyer agreed to it, and lower to mean that they did not agree to it. Next, we calculated the frequency of the proportion of agreed (score $>3$ ) to all operational procedures (score: 1-5). This is shown in Figure 2. Most buyers agreed to more than half of the operational procedures that were applicable for their most recent procurement $(\mathrm{M} \mathrm{.55,SD}=.25)$. Notably, the number of operational procedures agreed on was influenced neither by buyer profile nor by project category (smallest $p=.122$ ).

FIGURE 2

The Ratio of Agreed on Operational Procedures to Applicable Operational Procedures 


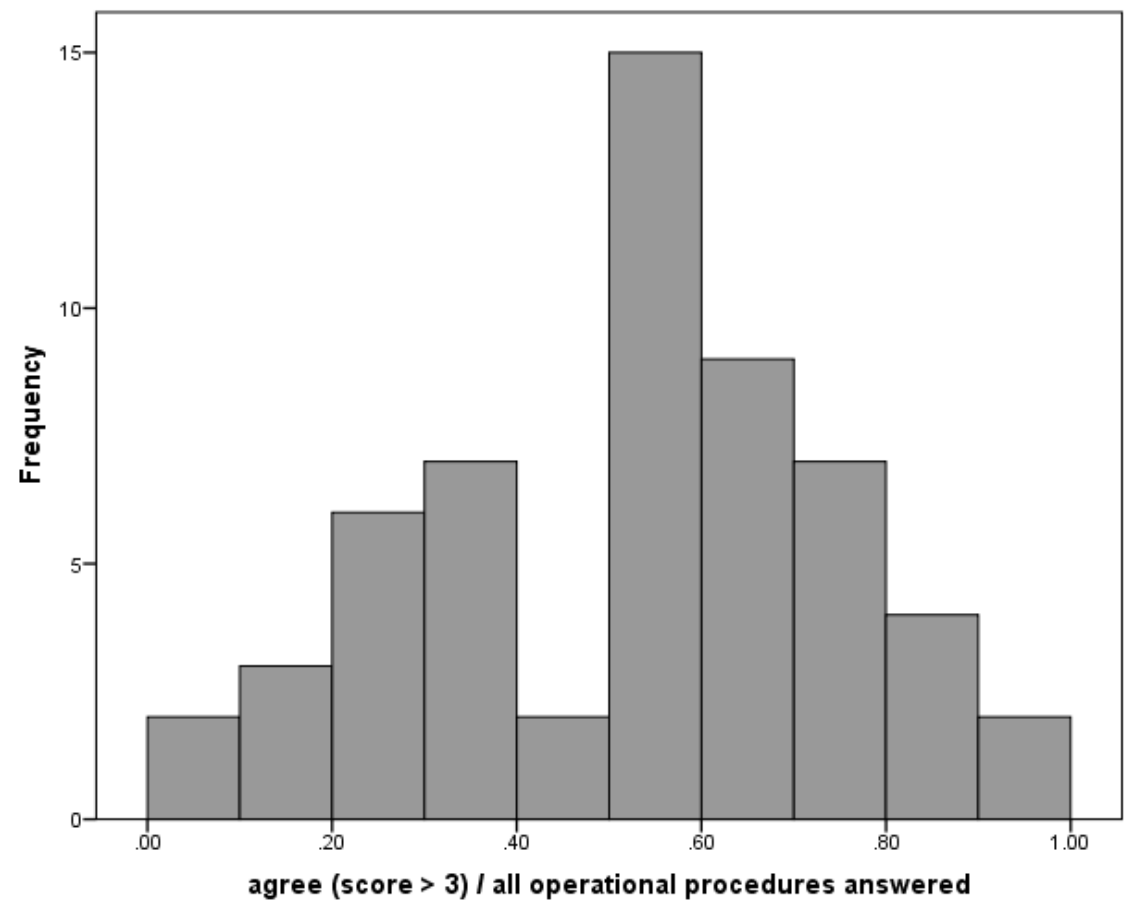

In summary, buyers with higher positions tended to search the market more than buyers with lower positions. Buyers typically referred to more than half of the operational procedures available.

\section{Analysis Based on Information Sources Grouping}

As addressed in the theoretical section above, operational procedures for considering environmental criteria can be seen from the viewpoint of information sources because each operational procedure is associated with an information source. We developed classifications by defining borders between buyer departments and organizations. This yielded three classifications: buyer internal information sources ("BIS"), in-house information sources ("InIS"), and external information sources ("ExtIS"). "BIS" concerns information sources found within procurement departments, "InIS" refers to sources within buyers' organizations but outside their procurement departments, and "ExtIS" concerns information sources outside the procurement organization. 
ANALYZING BUYER BEHAVIOR WHEN SELECTING GREEN CRITERIA

Table 5 shows how the operational procedures map onto those three categories. We link "PreUp," "Blev," "QulSpc," and "FolUsu" to BIS. Referring to previous projects ("PreUp") or usual practices ("FolUsu") means that buyers acquire information from a familiar experience or routine that they know from their prior working experience, so the information is located in the buyers' minds and accordingly in the procurement department. Individual belief ("Blev") relates to possible endogenous contributions to environmental issues. Understandings and attitudes toward environmental demands in multiple stages of procurement ("QulSpc") are interpreted as an aspect of the procurement department's norms. Therefore, "QuISpc" is part of "BIS."

Expertise in environmental aspects ("EnvExp"), instruction from another department ("ToUse"), and expertise in products ("ProExp") are related to intra-organizational resources. They make up the category of "InIS."

The market ("Mkt"), other public organizations ("OthAut"), and the governmental bodies ("IndReq" and "GudCri") are situated outside the organization. Accordingly they are labeled "ExtIS."

Based on these distinctions, we conducted a multivariate analysis. Again, we excluded "IndReq," as its formulation opens up an ambiguous interpretation. The average agreement scores are presented in Table 5 below.

A multivariate analysis of variance yielded no significant difference between the three categories; nor did any of the predictors (gender, experience, position, or project category) significantly predict agreement to all three categories. However, within subject effects for "BIS" and organizational size reached significance: $F(1,38)=5.044, p$ $=.031, \eta 2=.117$. And position influenced "InIS" $(F(2,38)=5.948, p$ $=.006, \eta 2=.238)$ and "ExtIS" $(F(2,38)=3.82, p=.031, \eta 2=.167)$. That is, buyers in bigger organizations tend to agree more on internal information sources ("BIS") than did buyers in smaller organizations; and buyers with higher positions tended to refer more to in-house and external information sources ("InIS") and "ExtIS" than buyers with less responsibility.

TABLE 5 


\section{Classification of Operational Procedures Based on Information Sources}

\begin{tabular}{|l|l|l|l|}
\hline Category & $\begin{array}{l}\text { Location of information } \\
\text { sources }\end{array}$ & $\begin{array}{l}\text { Operational } \\
\text { procedure (short } \\
\text { label) }\end{array}$ & $\begin{array}{l}\text { Mean } \\
\text { agreement } \\
\text { (SD) }\end{array}$ \\
\hline $\begin{array}{l}\text { Buyer internal } \\
\text { information } \\
\text { sources (BIS) }\end{array}$ & $\begin{array}{l}\text { in the procurement } \\
\text { department }\end{array}$ & $\begin{array}{l}\text { PreUp, Belv, } \\
\text { QuISpc, FolUsu }\end{array}$ & $3.14(.67)$ \\
\hline $\begin{array}{l}\text { In-house } \\
\text { information } \\
\text { sources (InIS) }\end{array}$ & $\begin{array}{l}\text { outside the procurement } \\
\text { department, but within } \\
\text { the organization }\end{array}$ & $\begin{array}{l}\text { EnvExp, ToUse, } \\
\text { ProExp, }\end{array}$ & $3.35(.91)$ \\
\hline $\begin{array}{l}\text { External } \\
\text { information } \\
\text { sources (ExtIS) }\end{array}$ & $\begin{array}{l}\text { outside the procurement } \\
\text { organization }\end{array}$ & $\begin{array}{l}\text { Mkt, OthAut, } \\
\text { LegDoc, GudCri }\end{array}$ & $3.36(.72)$ \\
\hline
\end{tabular}

\section{INTERPRETATION OF FINDING/DISCUSSION}

\section{General Buyer Behavior}

The first main finding regards what kind of behavioral procedures buyers tend to rely on when they consider environmental criteria. The belief that one can contribute to environmental issues as a buyer presented the highest agreement among all operational procedures and had the least score variance among the respondents. The social desirability bias may have contributed to this result. However, the difference of about 0.5 points ahead of the second procedure in goods procurement indicates that buyers truly believe their attitude in considering the uptake of environmental criteria can play an important role. This is similar to the finding of Grandia et al. (2015) that individual commitment or desire influences sustainable procurement behavior. Individual belief is not as prominent in service procurement. Still, it is ranked highest. When we compared the hypothetical procurement case with actual goods or services procurement, we found that the hypothetical goods procurement was similar to the actual goods procurement. This includes buyers procuring services, strengthening the validity of the survey.

Procedures that were regarded as most applicable in any procurement situation, either goods or services, actual or hypothetical, are valuing individual beliefs, checking legal documents, looking at other authorities, and considering different procurement requirements. These procedures are either endogenic to individual 
and procurement procedures or what buyers have available to them in any procurement project. It is quite natural to regard these as not irrelevant. In contrast, asking advice from environmental experts or product experts is not necessarily realistic or possible in every organization. Alternatively, respondents may think of themselves as experts. Accordingly, the procedures involving experts were more often regarded as irrelevant. To our surprise, we did not find that organizational size influenced the availability of internal experts. This might be because we had only two categories for organizational size, and our sample was skewed by larger organizations.

It is important to note that we only used the measure "internal environmental experts" in the survey. One respondent described in an open-ended question how his organization lacked environmental competencies and the time to learn and seriously consider environmental criteria. Another respondent indicated that his/her organization had used an external expert by stating that the organization had asked for advice from Miljøfyrtårn (Norway's most widely used certification scheme for enterprises managed by EcoLighthouse Foundation) or others. However, none of the other respondents implied that they used external environmental specialists. The use of external environmental expertise by buyers in the consideration of environmental criteria thus remains an unclear issue.

The survey result shows that buyers differ in terms of which and how many operational procedures they take into account. This is also supported by our interview data that show diversity in the applicable operational procedures mentioned in the three interviews. In addition, we see that buyers typically rely on more than half of the applicable information sources. Whereas considering all possible related information and aspects might be impossible due to time restrictions and the breadth of competences required, most buyers deemed half of the available information sources relevant for their latest project. This indicates that buyers process only a selected portion of information about their environment.

Influence of Buyer and Organization Characteristics on Buyer Behavior 
Our analysis revealed an interesting relationship between occupational position and buyer behavior. Buyers in higher positions tended to more actively search for information from in-house and external sources than buyers in lower positions. Those in higher positions were in particular more conscious of the importance of engagement with the market. This can be related to the notion of the cognitive frames of managers: information gathering strategies are acquired and learned through a manager's career history (Hahn, Preuss, Pinkse, \& Figge, 2014). Another explanation is that buyers in higher positions have more contact with external people and organizations than buyers in lower positions. This in turn may stimulate higher positioned buyers to look outside the organization.

Our analysis does not reveal that buyers' experience affects operational procedures. It has been argued that decision-makers' level of experience affects their selection of a decision strategy (Tsiros \& Heilman, 2005). Another study proposed that experience determined whether or not a person utilized a holistic strategy (Browne, Pitts, \& Wetherbe, 2007). Our result does not give support to these findings. A possible explanation may be that having experience as a procurement professional does not mean being experienced as an environmental management professional. We do not have any information about respondents' knowledge of environmental issues in the survey, except regarding the questions about the buyers' individual beliefs as to their contribution to environmental issues. Our result implies that having more experience as a procurement professional does not differentiate how one searches information regarding environmental criteria. However, our sample was not large enough to exclude this possibility.

With regard to gender, our results showed an insignificant influence on procedures taken or agreed on. As far as we know, little has been discussed about gender differences in the organizational buying behavior literature. When it comes to consumer behavior, existing studies argue that there is no significant difference between males and females in environmentally friendly buying behavior (Lee, Park, \& Han, 2013; Norazah, 2013). A majority of previous research (e.g., Stern, Dietz, \& Kalof, 1993) has found that women have stronger pro-environmental attitudes and show more concern about the environment in general, but not in particular towards environmental buying. These insights from the consumer research would suggest that female buyers search more actively and use more 
information sources than male buyers. However, this presumption could not be supported by our sample of buyers.

Regarding organizational size, it is commonly argued that larger firms have more internal resources available for the supplier selection process (e.g., Carr \& Pearson, 1999). When it comes to the literature on GPP implementation, there are different arguments related to organizational size. Michelsen and de Boer (2009) suggested a positive relationship between the level of GPP implementation and organizational size, while Testa, Grappio, Gusmerotti, Iraldo, and Frey (2015) did not find any support for a correlation between organizational size and the greenness of tenders. Our finding provides support for the existence of a relationship between organizational size and buyer behavior in considering environmental criteria. We found that buyers within larger organizations used buyer internal information sources (BIS) more than buyers from smaller organizations. This can be explained by larger organizations having more support, such as training and education for buyers, and more experience with a variety of procurement projects. Hence, BIS are developed to a "confidence level" for the buyer. We might also expect that larger organizations have more expertise within them; however, our analysis does not show any relationship between in-house information sources (e.g., environmental experts) and organizational size. A possible explanation may be that interdepartmental communications may become less effective as an organization grows (Barclay, 1991). In such cases, even though expertise is available, it might not be made use of. We heard a supporting statement for this non-use of existing expertise from one of the interviewees.

\section{Differences between Goods Procurement and Services Procurement}

We did not find any major differences between the types of procurement - that is, goods or services - when it came to the questions of which and how many procedures were seen as applicable. This means that our survey had good internal validity even though it was constructed based on interviews about goods procurement cases. A more detailed analysis, however, revealed that operational procedures were regarded as less applicable in service procurements than in goods procurements. It is especially notable that there were many fewer cases of service procurement in which 
buyers could draw on similar, previous projects and in which buyers could receive normative instructions from other departments within the organization. This implies that service procurement is subject to some variations in performance due to the heterogeneity of services (Mitchell \& Greatorex, 1993), and that previous projects are less informative to upcoming service procurements.

In terms of agreement levels, on average buyers of services had stronger agreement on each operational procedure. Especially other authorities and legal documents tended to be referred to more in service procurement than in good procurement. A possible explanation might be that for service procurement buyers tend to follow normative sources, perhaps because of the intangibility of services procurement (Lovelock, 1983). However, we would like to note that the environmental criteria used in service procurement are typically attributed to tangible products used in services (e.g., non-use of hazardous substances in cleaning detergent) or training (e.g., waste management training and cleaning methods training at a service company) (The European Commission, 2012). Service procurement could thus be seen as an application of goods procurement. In future research, one should look at how buyers perceive required technical and knowledge levels for setting environmental criteria in services compared to goods procurement.

\section{Heuristics and Bounded Rationality Identified in Buyer Behavior}

Among the operational procedures used as measurements in the survey, some can be associated with certain types of heuristics suggested in existing studies. For example, "PreUp" and "FolUsu" heavily rely on similar procurements that buyers have experienced previously. Buyers make use of environmental criteria from a familiar context, although it is usually not identical. This can be associated with "recognition heuristics," in which solutions are chosen because they are recognized or familiar compared to less familiar solutions (Goldstein \& Gigerenzer, 2002). Although Carter et al. (2007) use the term "bias" rather than heuristic, recognition heuristics seem to fit well with what they call "familiarity" and "habit" biases. "Familiarity bias" means that decision-makers are biased toward viewing more familiar events as being more likely than less familiar events. "Habit bias" concerns the situation where an alternative may be chosen because the decision-maker used it before and is used to it. Payne (1996) did not mention certain types of heuristics, but he argued that 
the ways in which individuals see or frame problems are built on prior knowledge, and this limits the search for new knowledge options. Giunipero, Hooker, and Denslow (2012) identified as one barrier to sustainable public procurement that it is "too difficult to change current practices." Alberg Mosgaard (2015) also pointed out the need to change habits of everyday practice in GPP. We did not see in our results that recognition or familiarity heuristics stood out in buyer behaviors; however, we argue that, in the GPP setting where things change over time, it is not desirable for buyers to rely on this recognition heuristic too much because buyers can possibly get stuck with the same or less evolved environmental criteria. It should be noted that one of the interviewees admitted that looking at similar previous procurements and copying them is the most efficient way of working, but probably not the most effective way of doing GPP.

"GudCri" is an operational procedure in which buyers borrow environmental criteria that are ready to use in national or multinational guidelines. This can be seen as "availability heuristics," since governmental or multinational guidelines include appealing information that buyers can easily retrieve. This conforms to the definitions used by Carter et al. (2007) and Tversky and Kahneman (1974). Given that "GudCri" is one of the most often-used operational procedures based on our results, this heuristic can be influential. If policymakers provided policies and guidance in an easily accessible way by including sample environmental criteria in a ready-to-use format, they could be very influential in enhancing green procurement in a certain direction.

"OthAut" concerns the buyer behavior of looking at what kind of environmental criteria other authorities have and copying them if they are applicable. This may be regarded as a subspecies of "imitation heuristics," that is, imitating peers' behavior as the "majority around" (Boyd \& Richerson, 2005). Carter et al. (2007), and Secchi and Bardone (2013) mention similar heuristics as "bandwagon effects" relating to the adaptation of a thought, behavior, or practice as a result of its popularity. This type of behavioral procedure can have both positive and negative effects. If an organization or group of organizations is recognized as an exemplar for its advanced and good green procurement practices and other authorities apply environmental criteria from the exemplar's projects to their projects, good green procurement practices will become disseminated. On the 
other hand, if authorities copy environmental criteria of other authorities without determining if they are being appropriately used, there is a risk of spreading an incorrect usage of environmental criteria. "OthAut" is highly used only in service procurements. However, we need to be aware of both the positive and negative effects of this heuristic.

We find a form of "satisficing" in "QulSpc." When a buyer sees that the procurement project addresses environmental aspects in the qualification and in the specification, the buyer judges that this is "good enough." Given all the possible roles played by environmental criteria throughout all the stages of a procurement process, this operational procedure seems "suboptimal" as it cannot guarantee that the supplier with the overall best environmental performance will be chosen. However, by already having used environmental criteria in the qualification phase and in the specifications, the suppliers are seen as having at least surpassed a basic aspiration level in terms of environmental performance; and hence, the buyer refrains from further search and deliberation activity in relation to environmental criteria at the award stage.

One of our findings, that higher position buyers tend to refer to external information sources more than lower positioned buyers, might be related to the question how buyers frame a situation, i.e., how broad or narrow they frame the procurement situation. Higher positioned buyers may deal with projects that require a broader set of criteria. We cannot, however, distinguish whether the career background of the higher position buyers gives them the expertise to handle more information sources (Hahn et al., 2015) or whether the procurement tasks handled by high positioned buyers require a broader set of information sources.

The selected use of available information sources indicates that buyers may be exposed to more information than they can process, which is similar to the argument regarding general decision-makers (e.g., Simon, 1947). Given that searching for information and formulating messages is costly (Van Zandt, 1998), and excess of information is one of the cognitive barriers in public procurement (Preuss \& Walker, 2011), buyers seem to consciously or unconsciously sense and process only a part of the information available. 
In summary, our survey gives an account of relying on heuristicsrelated operational procedures in the process of considering environmental criteria. Although our results do not describe which one is the most decisive behavior in the end, they indicate that these heuristics ("recognition," "availability," and "imitation," as well as "satisficing") are used by buyers in the context of GPP. Moreover, if one of them stands out from other operational procedures, either positive or negative effects can be expected. Our findings also indicate the presence of cognitive limitations in buyers.

\section{Research Limitation}

Regarding our research limitations, first, as abovementioned, we are not claiming that we have an exclusive list of operational procedures. Our list is derived from a limited number of interviews, and there is a possibility that interviewee informants did not share all the alternatives they had. To look into other possible behavioral procedures, we provided survey respondents an opportunity to describe additional procedures in a free-style question. As a result, we obtained other operational procedures, such as asking advice from environmental professional organizations and having a sort of template that provides guidelines for demands and criteria (each provided by one respondent). Still, our list captured typical operational procedures familiar to a large majority of our buyers.

Second, the nature and the size of the sample in the survey limited the extent of our interpretation. With a greater number of respondents and more variety of organizational sizes and project types, it would have been possible to find more associations between buyer behaviors and the task environment.

Last, our survey only shows the application of operational procedures without differentiating between the phase of searching for alternatives and the phase of choosing the criteria that are going to be used from the alternatives. Such differentiation may give more insight into buyer behavior.

\section{CONCLUSION AND IMPLICATIONS, FUTURE RESEARCH}

Through this study, we provide an important first step toward better understanding buyers' behavior in the public sector when they 
consider potential environmental criteria to be used in supplier selection. Through the survey, which was developed from initial interviews with public buyers, we obtained insight into what kind of factors can affect buyer's environmental behavior and how buyer's behavior present bounded rationality and heuristics.

\section{Main Conclusions}

Concerning the first research question, we found that three contextual factors in particular can affect a buyer's behavior: a buyer's occupational position, the type of procurement project, and organizational size. Buyers serving as department leaders or project leaders are inclined to refer to in-house and external information sources to a greater degree than buyers without such responsibilities. Buyers rate operational procedures differently depending on if they procure goods or services. The main differences are (1) a higher level of importance given to projects done by other authorities and to existing legal documents when buying services, and (2) a lower degree of applicability of previous project experiences and normative instructions when buying services. We provide potential explanations for these differences based on the nature of service procurement, that is, a lower degree of similarity between projects and the intangible nature of services. Buyers in larger organizations refer to internal information more often than those in smaller organizations. This might imply that larger organizations develop their internal information sources to a sufficient level for buyers to rely on.

Our study does not reveal any influence of gender or experience on buyers' behavior when it comes to environmental criteria considerations. Having long experience as a buyer does not seem to matter when considering environmental criteria in supplier selection.

When it comes to the second question about how bounded rationality is present in public buyers' behavior, we conclude that at least four operational procedures can be associated with particular heuristics from the behavioral literature: "recognition," "availability," and "imitation" heuristics, and "satisficing." As far as we are aware, our study is the first that empirically documents the use of these heuristics in a GPP setting. In addition, we argue that the result that shows department leaders' tendency to look at in-house and external information sources to a higher degree than normal buyers could mean that higher positioned buyers are more capable of information 
processing from a variety of sources. Or it could be argued that procurement projects that require highly positioned buyers demand broader information sources. We also found that buyers typically process only a part of the information available. This suggests that buyers normally have more information sources available than they can manage to use and that they necessarily have to prioritize the ones they actually use.

\section{Implications for Policy-Makers and Practitioners}

Based on our findings, we suggest the following implications for policymakers and practitioners. We structure the discussion of these implications by using Thai's (2001) public procurement system model. This model pictures public procurement as the dynamic interplay of five subsystems ("boxes," as referred to by Thai): policymaking and management (box 1), procurement regulations (box 2 ), authorization and appropriations (box 3 ), procurement function in operations (box 4), and feedback (box 5). We believe our findings have implications for each of these boxes and their interactions.

When it comes to box 1 (policy-making and management), GPP policy should recognize and further strengthen the personal, individual motivation of public buyers to contribute to GPP. Furthermore, this policy should be aimed at empowering public buyers by providing them with additional information about sustainability issues and organizational leeway to more effectively influence the buying process. Following the general discussion of the empowerment concept in Thomas and Velthouse (1990), this should lead to providing public buyers with additional authority, capacity, and motivational energy.

Second, we suggest that policy-makers be aware of the differences in buyers' behavior between goods and services procurement as observed in our study. The question is whether separate policies should be developed and communicated for these categories. Environmental issues in service procurement can be, in many cases, related to the physical equipment or resources used in performing the service. Policy aimed at facilitating buyers' ability to seek common approaches or increase their general knowledge about the differences between goods and services procurement could be a 
well-functioning solution instead of highlighting differences in terms of specific information and knowledge to be handled by buyers.

Third, policy-makers must acknowledge the heuristic nature of GPP. It is important to be aware of the different types of heuristics that buyers tend to rely on and even more important for policy-makers and buyers to understand the possible positive and especially negative effects of those heuristics - for example, the danger of inertia in GPP as discussed in relation to the recognition heuristic. This study also informs policy-makers on the information resources that are typically used in considering environmental criteria. For example, it appears that public buyers consider the use of external experts to be less attractive than other resources such as internal experts or legal documents. GPP policy could be aimed at making this resource more attractive.

Regarding box 2 (procurement regulations), the study underlines the importance of legal documents as a source of information for public buyers when establishing a set of environmental criteria. Effective communication of regulations and easy access to information about environmental criteria related to these regulations and their use are important aspects.

As Thai (2001) argues, the topic of box 3 (authorization and appropriations) is somewhat of a neglected topic in the public procurement literature. Following our recommendation under box 1 (policy-making and management) to strengthen the role of public buyers in general and to more firmly empower them as competent and motivated agents, specific attention could be paid to considering how they could contribute to the authorization of public procurement projects with regard to its environmental aspects.

Box 4 (procurement function in operations) is at the heart of executing, organizing, and managing daily procurement operations. Based on our findings, we derive several implications in relation to this topic. The importance of strengthening public buyers' general knowledge about sustainability issues has already been pointed out. This aspect is critical because inclusion of environmental criteria in tender documents is the first step towards green policy implementation (Amann et al., 2014) and buyers are usually the ones who decide on the wording in tender documents (personal communication, June 10, 2013). Competence in the area of sustainability, as our findings suggest, may be more relevant than the 
amount of general purchasing experience for how public buyers carry out and approach green supplier selection. This may also be important to consider in decisions regarding the internal organization of procurement and regarding recruitment of new buyers. Management should also consider the need for a human resource system of measuring the employees' attitudes toward environmental (or sustainability) issues in order to discover employees with an active attitude towards environmental issues and support the development of adequate career paths within procurement.

Last, but certainly not least, is box 5 containing the essential feedback loops in the public procurement system. It is important that policy-makers and management at regional and local units create and maintain systems in which information related to environmental criteria is easily available and updated so that public buyers can draw on and learn from the experiences of others and avoid the risk of using outdated or inappropriate environmental criteria. One could envisage a platform in which cases of inadequate use of environmental criteria can be discussed and shared. It is common that "best practices" or advanced green procurement cases are shared through websites or newsletters, but there are many things to learn from failure as well. As Thai (2001) argues, it is important to create feedback processes and loops in public procurement system work based on the experiences of public procurement professionals. This will make the use of heuristics such as imitation easier, while at the same time (because of the possibility to learn and discuss), reducing the risk of blindly and wrongly applying criteria observed through imitation.

\section{Future Research}

Useful avenues for future research would be to expand and replicate the work done in this paper. Research with a greater sample size is necessary to further validate and refine the results of this survey. There are also other possible variables that could be included in the survey, for example, "monetary value expectations for purchase products" and "time pressures." Another important direction for future research would be to study the use of heuristics in more detail, for example through close observations during procurement processes rather than only through interviews in retrospect. In that way, researchers could identify critical operational procedures that 
determine the selection of environmental criteria in tender documents and discuss how different heuristics work in combination with environmental criteria selection. One could also consider the use of quasi-experiments, in which public buyers are asked to select environmental criteria from sets of criteria provided by researchers. Mimicking realistic settings, the researchers could vary relevant situational parameters, such as the complexity of the procurement project, the time available, the number of decision-makers involved, and the extent to which various information sources are available.

\section{REFERENCES}

Amann, M., Roehrich, K., Eßig, M., \& Harland, C. (2014). "Driving Sustainable Supply Chain Management in the Public Sector." Supply Chain Management 19(3): 351-366.

Alberg Mosgaard, M. (2015). "Improving the Practices of Green Procurement of Minor Items." Journal of Cleaner Production, 90: 264-274.

Barclay, D. W. (1991). "Interdepartmental Conflict in Organizational Buying: The Impact of the Organizational Context." Journal of Marketing Research, 28(2): 145-159.

Barclay, D. W., \& Bunn, M. D. (2006). "Process Heuristics in Organizational Buying: Starting to Fill a Gap." Journal of Business Research, 59(2): 186-194.

Bendoly, E., Donohue, K., \& Schultz, K. L. (2006). "Behavior in Operations Management: Assessing Recent Findings and Revisiting Old Assumptions." Journal of Operations Management, 24(6): 737-752.

Bingham, C. B., \& Eisenhardt, K. M. (2011). "Rational Heuristics: the 'Simple Rules' that Strategists Learn from Process Experience." Strategic Management Journal, 32(13): 1437-1464.

Bouwer, M., de Jong, K., Jonk. M, Berman, T., Bersani, R., Lusser, H., Nissinen, A, Parikka, K., and Szuppinger, P. (2005). Green Public Procurement in Europe 2005 - Status Overview. Haarlem, The Netherlands: Virage Milieu \& Management bv.

Boyd, R., \& Richerson, P. J. (2005). The Origin and Evolution of Cultures (1st ed.). New York: Oxford University Press. 
ANALYZING BUYER BEHAVIOR WHEN SELECTING GREEN CRITERIA

Brammer, S., \& Walker, H. (2011). "Sustainable Procurement Practice in the Public Sector: An International Comparative Study". International Journal of Operation and Production Management, 31(4): 452-476.

Bratt, C., Hallstedt, S., Robèrt, K. H., Broman, G., \& Oldmark, J. (2013). "Assessment of Criteria Development for Public Procurement from a Strategic Sustainability Perspective." Journal of Cleaner Production, 52(0): 309-316.

Brossard, H. L. (1998). "Information Sources Used by an Organization During a Complex Decision Process: An Exploratory Study." Industrial Marketing Management, 27(1): 41-50.

Browne, G. J., Pitts, M. G., \& Wetherbe, J. C. (2007). “Cognitive Stopping Rules for Terminating Information Search in Online Tasks." MIS Quarterly, 31(1): 89-104.

Bunn, M. D. (1993). "Taxonomy of Buying Decision Approaches." Journal of Marketing, 57(1): 38-56.

Bunn, M. D., \& Clopton, S. W. (1993). "Patterns of Information Source Use Across Industrial Purchase Situations." Decision Sciences, 24(2): 457-478.

Carr, A. S., \& Pearson, J. N. (1999). "Strategically Managed Buyersupplier Relationships and Performance Outcomes." Journal of Operations Management, 17(5): 497-519.

Carter, C. R., Kaufmann, L., \& Michel, A. (2007). "Behavioral Supply Management: A Taxonomy of Judgment and Decision-making Biases." International Journal of Physical Distribution \& Logistics Management, 37(8): 631-669.

CEPS \& College of Europe (2012). The Uptake of Green Public Procurement in the EU27. Brussels, Belgium: European Union.

Chow, S. J. (2014). "Many meanings of 'Heuristic." The British Journal for the Philosophy of Science, 66(4): 977-1016.

Coggburn, J. D., \& Rahm, D. (2005). "Environmentally Preferable Purchasing: Who is Doing What in the United States?" Journal of Public Procurement, 5(1): 23-53. 
Cyert, R. M., \& March, J. G. (1963). A Behavioral Theory of the Firm. New Jersey: Prentice-Hall.

Cyert, R. M., \& March, J. G. (1992). A Behavioral Theory of the Firm ( $2^{\text {nd }}$ ed.). Malden, MA: Blackwell.

Dempsey, W. A. (1978). "Vendor Selection and the Buying Process." Industrial Marketing Management, 7(4): 257-267.

Faith-Ell, C., Balfors, B., \& Folkeson, L. (2006). "The Application of Environmental Requirements in Swedish Road Maintenance Contracts." Journal of Cleaner Production, 14(2): 163-171.

Flynn, A., \& Davis, P. (2014). "Theory in Public Procurement Research." Journal of Public Procurement, 14(2): 139-180.

Geng, Y., \& Doberstein, B. (2008). "Greening Government Procurement in Developing Countries: Building Capacity in China." Journal of Environmental Management, 88(4): 932-938.

Gigerenzer, G., \& Goldstein, D. G. (1996). "Reasoning the Fast and Frugal Way: Models of Bounded Rationality." Psychological Review, 103(4): 650-669.

Giunipero, L. C., Hooker, R. E., \& Denslow, D. (2012). "Purchasing and Supply Management Sustainability: Drivers and Barriers." Journal of Purchasing and Supply Management, 18(4): 258-269.

Goldstein, D. G., \& Gigerenzer, G. (2002). "Models of Ecological Rationality: The Recognition Heuristic." Psychological Review, 109(1): 75-90.

Grandia, J., Steijn, B., \& Kuipers, B. (2015). "It Is Not Easy Being Green: Increasing Sustainable Public Procurement Behaviour." Innovation: The European Journal of Social Science Research, 28(3): 243-260.

Grandori, A. (1984). "A Prescriptive Contingency View of Organizational Decision-making." Administrative Science Quarterly, 29(2): 192-209.

Grønhaug, K. (1975). "Autonomous vs. Joint Decisions in Organizational Buying." Industrial Marketing Management, 4(5): 265-271. 
ANALYZING BUYER BEHAVIOR WHEN SELECTING GREEN CRITERIA

Guercini, S., La Rocca, A., Runfola, A., \& Snehota, I. (2015). "Heuristics in Customer-supplier Interaction." Industrial Marketing Management, 48: 26-37.

Hahn, T., Preuss, L., Pinkse, J., \& Figge, F. (2014). "Cognitive Frames in Corporate Sustainability Managerial Sensemaking with Paradoxical and Business Case Frames." Academy of Management Journal, 39(4): 463-487.

Igarashi, M., de Boer, L., \& Michelsen, O. (2015). "Investigating the Anatomy of Supplier Selection in Green Public Procurement." Journal of Cleaner Production, 108(Part A): 442-450.

Kippo-Edlund, P., Hauta-Heikkilä, H., Miettinen, H., Nissinen, A. (2005). Measuring the Environmental Soundness of Public Procurement in Nordic Countries. Copenhagen, Denmark: Nordic Counsel of Ministers.

Lee, E., Park, N-K., \& Han, J. H. (2013). “Gender Difference in Environmental Attitude and Behaviors in Adoption of Energyefficient Lighting at Home." Journal of Sustainable Development, 6(9): 36-50.

Li, L., \& Geiser, K. (2005). “Environmentally Responsible Public Procurement (ERPP) and Its Implications for Integrated Product Policy (IPP)." Journal of Cleaner Production, 13(7): 705-715.

Loock, M., \& Hinnen, G. (2015). "Heuristics in Organizations: A Review and a Research Agenda." Journal of Business Research, 68(9): 2027-2036.

Lopes, L. L. (1992). "Three Misleading Assumptions in the Customary Rhetoric of the Bias Literature." Theory \& Psychology, 2(2): 231236.

Lovelock, C. H. (1983). "Classifying Services to Gain Strategic Marketing Insights." Journal of Marketing, 47(3): 9-20.

Lundberg, S., \& Marklund, P. O. (2013). "Green Public Procurement as an Environmental Policy Instrument: Cost Effectiveness." Environmental Economics, 4(4): 75-83.

Lundberg, S., Marklund, P. O., Strömbäck, E., \& Sundström, D. (2015). “Using Public Procurement to Implement Environmental 
Policy: An Empirical Analysis." Environmental Economics and Policy Studies, 17(4): 487-520.

Mantel, S. P., Tatikonda, M. V., \& Liao, Y. (2006). “A Behavioral Study of Supply Manager Decision-making: Factors Influencing Make versus Buy Evaluation." Journal of Operations Management, 24(6): 822-838.

March, J. G., \& Simon, H. A. (1958). Organizations. Oxford, England: Wiley.

Michelsen, O., \& de Boer, L. (2009). "Green Procurement in Norway; A Survey of Practices at the Municipal and County Level." Journal of Environmental Management, 91(1): 160-167.

Mitchell, V. W., \& Greatorex, M. (1993). "Risk Perception and Reduction in the Purchase of Consumer Services." The Service Industries Journal, 13(4): 179-200.

Moriarty, Jr. R. T., \& Spekman, R. E. (1984). “An Empirical Investigation of the Information Sources Used during the Industrial Buying Process." Journal of Marketing Research, 21(2): 137-147.

Morse, J. M. (2003). "Principles of Mixed Methods and Multiplemethod Research Design." In. A. Tashakkori \& C. Teddlie (Eds.), SAGE Handbook of Mixed Methods in Social and Behavioral Research (pp. 189-208). Thousand Oaks, CA: Sage.

Nelson, K. L., Wood, C. H., \& Gabris, G. T. (2011). “Innocation Management in Local Government: An Empirical Analysis of Suburban Municipalities." International Journal of Organization Theory and Behavior, 14(3): 301-328.

New, S., Green, K., Morton, B. (2002). "An Analysis of Private versus Public Sector Responses to the Environmental Challenges of the Supply Chain." Journal of Public Procurement, 2(1): 93-105.

Newell, A., \& Simon, H. A. (1972). Human Problem Solving. New Jersey: Prentice-Hall.

Nissinen, A., Parikka-Alhola, K., \& Rita, H., (2009). “Environmental Criteria in the Public Purchases above the EU Threshold Values by Three Nordic Countries: 2003 and 2005." Ecological Economics, 68(6): 1838-1849. 
ANALYZING BUYER BEHAVIOR WHEN SELECTING GREEN CRITERIA

Norazah, M. S. (2013). "Young Consumer Ecological Behaviour." Management of Environmental Quality, 24(6): 726-737.

OECD (2012). Behavioural Economics and Environmental Policy Design, Project Description. [Online]. Available at http://www.oecd.org/env/consumption-innovation/Behavioural\% 20Economics\%20and\%20Environmental\%20Policy\%20Design.pd f. [Retrieved October 10, 2015].

Palmujoki, A., Parikka-Alhola, K., \& Ekroos, A. (2010). “Green Public Procurement: Analysis on the Use of Environmental Criteria in Contracts." Review of European Community \& International Environmental Law, 19(2): 250-262.

Parikka-Alhola, K. (2008). "Promoting Environmentally Sound Furniture by Green Public Procurement. Ecological Economics, 68(1-2): 472-485.

Parikka-Alhola, K., Nissinen, A., \& Ekroos, A. (2006). "Green Award Criteria in the Most Economically Advantageous Tender in Public Purchasing." In K. V. Thai \& G. Piga (Eds.), Advancing public procurement (pp. 257-279). Boca Raston, FL: Academic Press.

Payne, J. W., Bettman, J. R., \& Johnson, E. J. (1993). The Adaptive Decision Maker. Cambridge, UK: Cambridge University Press.

Payne, J. W. (1996). "The Scarecrow's Search: A Cognitive Psychologist's Perspective on Organizational Decision Making." In Z. Shapira (Eds.), Organizational Decision Making (pp. 353-374). Cambridge, UK : Cambridge University Press.

Preuss, L. (2002). “Green Light for Greener Supply.” Business Ethics: A European Review, 11(4): 308-317.

Preuss, L. (2007). "Buying into Our Future: Sustainability Initiatives in Local Government Procurement." Business Strategy and the Environment, 16(5): 354-365.

Preuss, L., \& Walker, H. (2011). "Psychological Barriers in the Road to Sustainable Development: Evidence from Public Sector Procurement." Public Administration, 89(2): 493-521.

Qualls, W. J., \& Puto, C. P. (1989). "Organizational Climate and Decision Framing: An Integrated Approach to Analyzing Industrial 
Buying Decisions." Journal of Marketing Research, 26(2): 179192.

Riedl, D. F., Kaufmann, L., Zimmermann, C., \& Perols, J. L. (2013). "Reducing Uncertainty in Supplier Selection Decisions: Antecedents and Outcomes of Procedural Rationality." Journal of Operations Management, 31(1-2): 24-36.

Rizzi, F., Frey, M., Testa, F., \& Appolloni, A. (2014). “Environmental Value Chain in Green SME Networks: the Threat of the Abilene Paradox." Journal of Cleaner Production, 85(0): 265-275.

Robinson, P. J., Faris, C. W., \& Wind, Y. (1967). Industrial Buying and Creative Marketing. Boston, MA: Allyn and Bacon.

Secchi, D., \& Bardone, E. (2013). "Socially Distributed Cognition and Intra-oraganizational Bandwagon: Theoretical Framwork, Model and Simulation." International Journal of Organization Theory and Behavior, 16(4): 521-572.

Sheth, J. N. (1973). “A Model of Industrial Buyer Behavior." Journal of Marketing, 37(4): 50-56.

Simon, H. A. (1947). Administrative Behavior (1 ${ }^{\text {st }}$ ed.). New York: Free Press.

Simon, H. A. (1955). "A Behavioral Model of Rational Choice." The Quarterly Journal of Economics, 69(1): 99-118.

Simon, H. A. (1957). Models of Man: Social and Rational : Mathematical Essays on Rational Human Behavior in a Social Setting. New York: Wiley.

Simon, H. A. (1990). "Invariants of Human Behavior." Annual Review of Psychology, 41(1): 1-20.

Sporrong, J., \& Bröchner, J. (2009). "Public Procurement Incentives for Sustainable Design Services: Swedish Experiences." Architectural Engineering and Design Management, 5(1-2): 2435.

Stern, P. C., Dietz, T., \& Kalof, L. (1993). "Value Orientations, Gender, and Environmental Concern." Environment and Behavior, 25(3): 322-347.

Swanson, M., Weissman, A., Davis, G., Socolof, M. L., \& Davis, K. (2005). "Developing Priorities for Greener State Government 
ANALYZING BUYER BEHAVIOR WHEN SELECTING GREEN CRITERIA

Purchasing: a California Case Study." Journal of Cleaner Production, 13(7): 669-677.

Tashakkori, A., \& Teddlie, C. (2003). Handbook of Mixed Methods in Social \& Behavioral Research. Thousand Oaks, CA: SAGE.

Testa, F., Grappio, P., Gusmerotti, N., Iraldo, F., \& Frey, M. (2015). "Examining Green Public Procurement Using Content Analysis: Existing Difficulties for Procurers and Useful Recommendations." Environment, Development and Sustainability, 18(1): 197-219.

Testa, F., Iraldo, F., Frey, M., \& Daddi, T. (2012). "What Factors Influence the Uptake of GPP (Green Public Procurement) Practices? New Evidence from an Italian Survey." Ecological Economics, 82(0): 88-96.

Thai, K.V. (2001). "Public Procurement Re-examined." Journal of Public Procurement, 1: 9-50.

The Commission of the European Communities, (2008). Communication from the Commission to the European Parliament, the Council, the European Economic and Social Committee and the Committee of the Regions: Public Procurement for a Better Environment.Brussels: European Union.

The European Commission. (2012). EU GPP Criteria for cleaning products \& services. [online] Available at http://ec.europa.eu/ environment/gpp/eu_gpp_criteria_en.htm. [Retrieved October 22, 2015].

Thomas, K. W., \& Velthouse, B. A. (1990). "Cognitive Elements of Empowerment: An "Interpretive" Model of Intrinsic Task Motivation." Academy of Management Review, 15(4): 666-681.

Tsiros, M., \& Heilman, C. M. (2005). "The Effect of Expiration Dates and Perceived Risk on Purchasing Behavior in Grocery Store Perishable Categories." Journal of Marketing, 69(2): 114-129.

Tversky, A., \& Kahneman, D. (1974). “Judgment under Uncertainty: Heuristics and Biases." Science, 185(4157): 1124-1131.

Umpfenbach, K., \& Colleagues Ecologic Institute. (2014). Influences on consumer behaviour: Policy implications beyond nudging. [Online] Available at http://ec.europa.eu/environment/enveco/ 
economics__policy/pdf/Behaviour\%20Policy\%20Brief.pdf. [Retrievd October 10, 2015].

Uttam, K., Faith-Ell, C., \& Balfors, B. (2012). "ElA and Green Procurement: Opportunities for Strengthening Their Coordination." Environmental Impact Assessment Review, 33(1): 73-79.

Van Zandt, T. (1998). "Organizations with an Endogenous Number of Information Processing Agents." In M. Majumdar (Eds.), Organizations With Incomplete Information (pp. 239-305). Cambridge, UK: Cambridge University Press.

Varnäs, A., Balfors, B., \& Faith-Ell, C. (2009). "Environmental Consideration in Procurement of Construction Contracts: Current Practice, Problems and Opportunities in Green Procurement in the Swedish Construction Industry." Journal of Cleaner Production, 17(13): 1214-1222.

Walker, H., Di Sisto, L., \& McBain, D. (2008). "Drivers and Barriers to Environmental Supply Chain Management Practices: Lessons from the Public and Private Sectors." Journal of Purchasing and Supply Management, 14(1): 69-85.

Webster, J. F. E., \& Wind, Y. (1972). "A General Model for Understanding Organizational Buying Behavior." Journal of Marketing, 36(2): 12-19.

Wilson, E. J., McMurrian, R. C., \& Woodside, A. G. (2001). "How Buyers Frame Problems: Revisited." Psychology and Marketing, 18(6): 617-655.

Zhu, Q., Sarkis, J., \& Lai, K-H. (2013). "Institutional-based Antecedents and Performance Outcomes of Internal and External Green Supply Chain Management Practices." Journal of Purchasing and Supply Management, 19(2): 106-117.

\section{APPENDIX A}

Drivers and Barriers of GPP

\begin{tabular}{|l|c|c|c|}
\hline Panel A: Drivers, Incentives, Determinants, and Antecedents \\
\hline & Individual Level & Organizational Level & $\begin{array}{c}\text { Inter-Orga- } \\
\text { nizational } \\
\text { Level }\end{array}$ \\
\hline
\end{tabular}


ANALYZING BUYER BEHAVIOR WHEN SELECTING GREEN CRITERIA IN PUBLIC PROCUREMENT

\begin{tabular}{|c|c|c|c|c|c|c|c|c|c|c|c|c|c|c|c|}
\hline & $\frac{\frac{0}{2}}{\frac{10}{10}}$ & 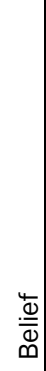 & 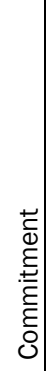 & 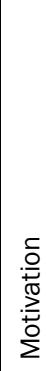 & 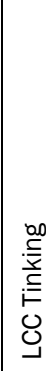 & 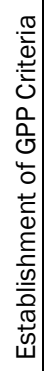 & 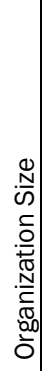 & 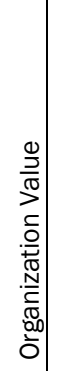 & 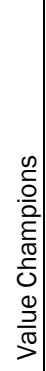 & 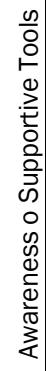 & 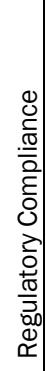 & 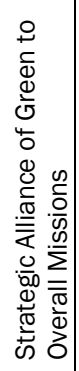 & 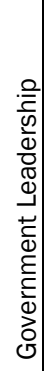 & 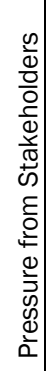 & 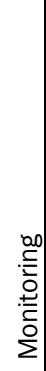 \\
\hline \multicolumn{16}{|l|}{ Coggburn and Rahm (2005) } \\
\hline \multicolumn{16}{|l|}{ Faith-Ell et al. (2006) } \\
\hline Geng and Doberstein (2008) & & & & & $\mathrm{x}$ & $\mathrm{x}$ & & & & & & & & $\mathrm{x}$ & \\
\hline Grandia et al. (2015) & $\mathrm{x}$ & $\mathrm{x}$ & & & & & & & & & & & & & \\
\hline Li and Geiser (2005) & & & $\mathrm{x}$ & $\mathrm{x}$ & & & & & & & & & & & \\
\hline Michelsen and de Boer (2009) & & & & & & & $\mathrm{x}$ & & & & & & & & \\
\hline New et al. (2002) & & & & & & & & & & & & $\mathrm{x}$ & & & \\
\hline \multicolumn{16}{|l|}{ Palmujoki et al. (2010) } \\
\hline \multicolumn{16}{|l|}{ Preuss (2007) } \\
\hline \multicolumn{16}{|l|}{ Rizzi et al. (2014) } \\
\hline Testa et al. (2012) & & & & & & & & & & $\mathrm{x}$ & & & & & \\
\hline
\end{tabular}


APPENDIX A (Continued)

\begin{tabular}{|c|c|c|c|c|c|c|c|c|c|c|c|c|c|}
\hline \multicolumn{14}{|c|}{ Panel A: Drivers, Incentives, Determinants, and Antecedents } \\
\hline & \multicolumn{4}{|c|}{ Individual Level } & \multicolumn{6}{|c|}{ Organizational Level } & \multicolumn{3}{|c|}{$\begin{array}{c}\text { Inter-Orga- } \\
\text { nizational } \\
\text { Level }\end{array}$} \\
\hline & $\frac{\frac{0}{5}}{\frac{\pi}{7}}$ & 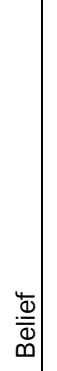 & 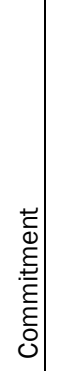 & 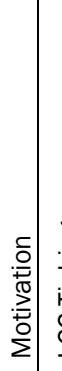 & 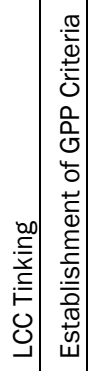 & 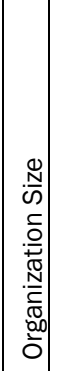 & $\begin{array}{l}\frac{0}{3} \\
\frac{3}{\pi} \\
2 \\
\frac{1}{0} \\
.0 \\
\frac{0}{0} \\
\stackrel{N}{0} \\
\frac{1}{0} \\
0.0 \\
0 \\
0\end{array}$ & 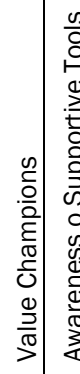 & 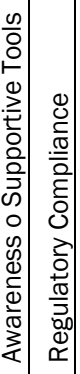 & 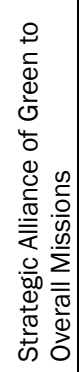 & 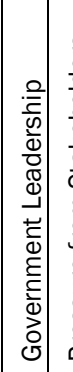 & 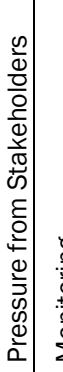 & \\
\hline \multicolumn{14}{|l|}{ Varnas et al. (2009) } \\
\hline Walker et al. (2008) & & & & & & & $\mathrm{x}$ & $\mathrm{x}$ & $\mathrm{x}$ & & & $\bar{x}$ & \\
\hline Zhu et al. (2013) & & & & & & & & & $\mathrm{x}$ & & & $x$ & \\
\hline \multicolumn{14}{|l|}{ Panel B: Barriers, and Obstacles } \\
\hline & \multicolumn{7}{|c|}{ Individual Level } & \multicolumn{3}{|c|}{\begin{tabular}{|c|}
$\begin{array}{c}\text { Organizational } \\
\text { Level }\end{array}$ \\
\end{tabular}} & \multicolumn{3}{|c|}{\begin{tabular}{|c|} 
Inter-Orga- \\
nizational \\
Level
\end{tabular}} \\
\hline & 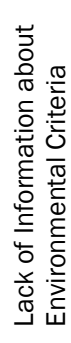 & & 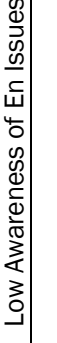 & 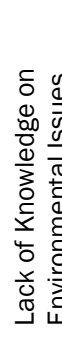 & 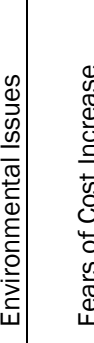 & 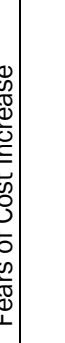 & 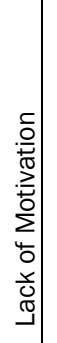 & 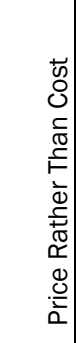 & 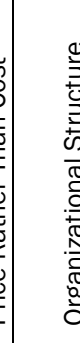 & $\begin{array}{l}\frac{1}{0} \\
0 \\
0 \\
0 \\
0 \\
\frac{0}{0} \\
0 \\
00 \\
0 \\
0 \\
0 \\
0 \\
0 \\
0 \\
4 \\
0 \\
\frac{1}{0} \\
0 \\
0\end{array}$ & 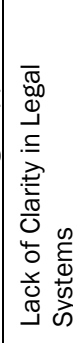 & 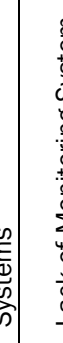 & \\
\hline Coggburn and Rahm (2005) & $\mathrm{x}$ & $\mathrm{x}$ & & & & & & & $\mathrm{x}$ & & & & \\
\hline Faith-Ell et al. (2006) & & & & & & & & & & & & $x$ & \\
\hline Geng and Doberstein (2008) & $x$ & $x$ & & & & & & $\mathrm{x}$ & & & $\mathrm{x}$ & & \\
\hline Grandia et al. (2015) & & & & & & & & & & & & & \\
\hline Li and Geiser (2005) & & & & & & $x$ & $x$ & & $\mathrm{x}$ & & & & \\
\hline Michelsen and de Boer (2009 & & & & $\mathrm{x}$ & & & & & & & & & \\
\hline New et al. (2002) & & & & & & & & & & & & & \\
\hline Palmujoki et al. (2010) & & & & & & & & & & & $\mathrm{x}$ & & \\
\hline Preuss (2007) & & & & & & & & & & $x$ & & & \\
\hline Rizzi et al. (2014) & $\mathrm{x}$ & & & & & & & & & $x$ & & & \\
\hline Testa et al. (2012) & & & & & & & & & & & & & \\
\hline Varnas et al. (2009) & & & & $\mathrm{x}$ & $\mathrm{x}$ & & & & & & & & \\
\hline Walker et al. (2008) & & & & & & & & & & & & & \\
\hline Zhu et al. (2013) & & & & $\mathrm{x}$ & & & & & & & & & \\
\hline
\end{tabular}


ANALYZING BUYER BEHAVIOR WHEN SELECTING GREEN CRITERIA

\section{APPENDIX B}

\section{Main questions in the Survey (translated from Norwegian into} English)

Question: How much do you agree on each item? Please think of one of the latest procurement projects that you have described in the previous question. Choose "not relevant" if you do not have such resources/sources available. For example, regarding item12, if Difi has not published a set of recommended environmental criteria for the product group, choose "not relevant" (options are; strongly agree, agree, neither agree nor disagree, disagree, strongly disagree, and not relevant).

Item 1 (PreUp): I look at what we have done in previous similar projects and update what should be changed.

Item 2 (Belv): I believe that one can contribute to environmental issues as a buyer.

Item 3 (EnvExp): I consult with an environmental expert in our organization.

Item 4 (Mkt): I investigate what is state of the art in the supply market.

Item 5 (OthAut): I check similar procurement projects done by other authorities.

Item 6 (LegDoc): I check relevant legal documents and see what criteria should be met.

Item 7 (ToUse): I apply the environmental criteria that we are told to use (by a central procurement department or any other internal team).

Item 8 (QulSpc): If there are a lot of qualifications and specifications, the award criteria need not be so powerful.

Item 9 (ProExp): I ask a product expert on our project team to give advice.

Item 10 (IndReq): I consider environmental standards in the industry (but then I do not demand some aspects)

Item 11 (FolUsu): I apply environmental criteria that we usually use in similar product procurements. 
Item 12 (GudCri): I look at the environmental criteria recommended by Difi* or the EU guideline.

*Difi: "Direktoratet for forvaltning og IKT," under Fornyings- og administrasjons- og kirkedepartementet (FAD), the Norwegian agency for public management and eGovernment.

Same questions for a hypothetical Google Glass procurement project 